\title{
Biofunctional activity of tortillas and bars enhanced with nopal. Preliminary assessment of functional effect after intake on the oxidative status in healthy volunteers
}

\author{
Juan Carlos Guevara-Arauza1*, José de Jesús Órnelas Paz², Sergio Rosales Mendoza', Ruth Elena Soria Guerra',
} Luz María Teresita Paz Maldonado', Diana Jaqueline Pimentel González ${ }^{3}$

\begin{abstract}
Background: Prickly pear cactus stem (nopal) has been used in folk medicine and a raw material since ancient times. Stems have been proved to possess components with valuable biological activities: anti inflamatory, antioxidant, antiulcerogenic, hypoglycemic, and so forth. Nowadays, people consume foods not only to cover the nutritional requirements, they also demand for healty, natural and convenient foods that show biological activity. This study evaluated the bio-functional effects of consuming tortillas or bars (filled with prickly pear fruit jam) supplemented or not with nopal dietary fiber.
\end{abstract}

Results: The addition of nopal increased the fiber and polyphenols content in both tortillas (16.67\%, $2.33 \mathrm{mg}$ QE/L) and bars (13.79\%, $1.99 \mathrm{mg}$ QE/L). Furthermore the trolox equivalent antioxidant capacity (TEAC, $1.47 \mathrm{mmol} / \mathrm{L}$ ), polyphenols $(7.67 \mathrm{mg}$ QE/L) and vitamin C $(77.91 \mu \mathrm{mol} / \mathrm{L})$ showed increased levels in volunteer's plasma after intake. Also lower levels of glucose $(4.43 \mathrm{mmol} / \mathrm{L})$, total cholesterol $(4.27 \mathrm{mmol} / \mathrm{L}), \mathrm{LDL}(1.96 \mathrm{mmol} / \mathrm{L})$ and triglycerides $(1.54 \mathrm{mmol} / \mathrm{L})$ were observed in plasma after the supplementation scheme with nopal-based tortilla, while GSH:GSSG ratio in erythrocytes was higher.

Conclusions: The results suggested that the intake of nopal-based tortillas with high content in fiber and antioxidant compounds can help to improve the overall oxidative status in healthy humans, which can reduce the risk of some chronic diseases. In addition, these products showed suitable physicochemical characteristics to be marketed.

\section{Background}

Several researches have showed that a regular or intensive intake of horticultural products can reduce the risk of chronic degenerative diseases such as cancer and cardiovascular diseases, in which oxidative damage is an important etiologic factor [1]. These benefits are mainly attributed to the antioxidant compounds and dietary fiber (DF) present in fruits and vegetables [2]. The DF is defined as carbohydrate polymers with 10 or more monomeric units which are not hydrolyzed by endogenous enzymes in the human small intestine, having

\footnotetext{
* Correspondence: carlos.guevara@uaslp.mx

${ }^{1}$ Centro de Investigación y Estudios de Posgrado (CIEP), Universidad

Autónoma de San Luis Potosí, SLP,78290, México C.P

Full list of author information is available at the end of the article
}

beneficial effects on health. This includes natural and synthetic DF. The DF can be supplied by normal food intake, including a diet with high content of DF or as an ingredient obtained via enzymatic, physical or chemical processes using different raw materials. The synthetic DF covers those synthetic polymers that have shown beneficial physiological effects to health [3].

Recently more sources of fiber are being evaluated in order to provide functional properties such as the water holding capacity and improvement in mechanical and rheological properties, among others [4]. Horticultural products have a balanced content of soluble and insoluble DF, so these can be suitable for enriching products with DF [5]. Due to the increasing consumer demand for convenient, healthy and natural foods and beverages, various attempts are being carried out with the aim of 
improving the nutritional value of products by changing the nutritional composition [6]. In Mexico, nopal is integrated as part of a healthy diet due to its high fiber content with concentrations of 40-60 g/100 g dry weight (dw) and the presence of total phenolic compounds (free and conjugated) with concentrations of 80-90 mg/ $100 \mathrm{~g} \mathrm{dw}$, including (2R,3R)-3,5,7-trihydroxy-2-(4-hydroxyphenyl)-2,3-dihydrochromen-4-one (aromadendrin), (2R,3R)-2-(3,4-dihydroxyphenyl)-3,5,7-trihydroxy-2,3dihydrochromen-4-one (taxifolin or dihydroquercetin), 3,5,7-trihydroxy-2-(4-hydroxy3-methoxyphenil)chromen4-one (isorhamnetin), 5,7-dihydroxy-2-(4-hydroxyphenyl)8-[(2S,3R,4R,5S,6R)-3,4,5-trihydroxy-6-(hydroxymethyl) oxan-2-yl]chromen-4-one (vitexin), 3,5,7-trihydroxy-2-(4hydroxyphenyl)chromen-4-one (kaempferol), 2-(3,4-Dihydroxyphenyl)-3,5,7-trihydroxy-4H-1-benzopyran-4-one dihydrate (quercetin) and derivatives like 3,5,7-trihydroxy2-(3,4,5-trihydroxyphenyl)chromen-4-one (myricitin), 2-(3,4-dihydroxyphenyl)-5,7-dihydroxy-8-[(2S,3R,4R, 5S,6R)-3,4,5-trihydroxy-6-(hydroxymethyl)oxan-2-yl]chromen-4-one (orientin) and some derivatives of pyrone [7]. However, the presence of flavones and flavanones in nopal has not been reported. On the other hand, the reported concentrations of phenolic compounds in prickly pear cactus fruit ranged $30-40 \mathrm{mg} / 100 \mathrm{~g} \mathrm{dw}$, while the fiber content is ranged 20-25 g/100 g dw [8]. Phenolic compounds from nopal have showed antioxidant, anticarcinogenic, anti inflammatory, analgesic, antiulcerogenic, hypoglycemic, hypolipidemic and hypocholesterolemic properties [9].

The aerobic metabolism is characterized by a constant production of mainly oxygen reactive species. Even in healthy subjects, pathophysiological events can be elicited when the generation of pro-oxidants exceeds the cellular capacity for self-protection mediated by some antioxidant defense systems [10]. Since phytochemicals with antioxidant activity in fruits and vegetables are responsible for opposite effects, the development of new products made with horticultural products can generate a wide range of functional foods [11].
The objective of this study was to produce nopal-based tortillas and bars, to characterize some physicochemical parameters [chemical composition, color, hardness, water activity $\left(\mathrm{a}_{\mathrm{w}}\right)$ ] and to evaluate its potential as functional food, measuring the effect of their ingestion over 3 weeks in the oxidative status (antioxidant capacity and oxidative stress biomarkers) of healthy volunteers.

\section{Results and Discussions}

\section{Physicochemical parameters of tortillas and bars}

In order to gain knowledge about the physicochemical characteristics of tortillas and bars supplemented $(+\mathrm{NDF})$ or not (-NDF) with nopal dietary fiber as well as bars filled with prickly pear fruit jam (PPJ), comparative analyses were carried out for these formulations.

\section{Analysis of total polyphenols}

Phenolic compounds content was increased with the addition of nopal in both tortillas and bars (Table 1). Changes in total phenols content between different formulations of bars and tortillas can be the result of different degrees of interaction between phenolic compounds and formulation components (dietary fiber and protein) [12]. It is known that thermal treatment induces oxidative condensation producing complexes, via multiple hydrogen bonds between the hydroxyl groups of polyphenols and carboxyl groups derived of pectin polysaccharides and/or proteins present in the formulation. However, long term exposure to high temperatures induce degradation of these thermolabile complexes causing an increase in phenols extracted from both bars and tortillas [13]. These interactions could be involved in the higher content of phenolic compounds. However more studies should be conducted to provide further explanation of this observed finding. No change in the polyphenols content was observed by addition of PPJ to the bars.

\section{Total dietary fiber, ash, proteins and lipids}

The addition of nopal to the formulation of tortillas and bars increased the dietary fiber content (16.67\%; 13.79\%,

Table 1 Physicochemical analysis in nopal-based tortillas and bars

\begin{tabular}{|c|c|c|c|c|c|c|c|c|c|}
\hline Bars & $\begin{array}{c}\text { Total } \\
\text { polyphenols } \\
\text { (mg QE/100 g) } \\
\end{array}$ & $\begin{array}{l}\text { Dietetic fiber } \\
\text { (\%) }\end{array}$ & Ash (\%) & $\begin{array}{l}\text { Proteins * } \\
(\%)\end{array}$ & Lipids (\%) & $\begin{array}{l}\text { Humidity } \\
\text { (\%) }\end{array}$ & $a_{w}$ & Hardness (N) & Color $\left(\Delta E^{*}\right)$ \\
\hline - NDF - PPJ & $1.39 \pm 0.02$ & $2.57 \pm 0.15$ & $0.74 \pm 0.05$ & $2.34 \pm 0.06$ & $7.55 \pm 0.05$ & $5.63 \pm 0.18$ & 0.45 & $63.21 \pm 2.18$ & \\
\hline - NDF + PPJ & $1.43 \pm 0.07$ & $2.94 \pm 0.11$ & $0.87 \pm 0.08$ & $2.07 \pm 0.09$ & $7.52 \pm 0.24$ & $5.66 \pm 0.62$ & 0.45 & $61.17 \pm 4.19$ & $3.46 \pm 2.32$ \\
\hline + NDF - PPJ & $1.87 \pm 0.05^{\mathrm{a}}$ & $13.20 \pm 0.96^{\mathrm{a}}$ & $1.03 \pm 0.05^{\mathrm{a}}$ & $1.07 \pm 0.06^{\mathrm{a}}$ & $6.77 \pm 0.11^{a}$ & $6.78 \pm 0.40^{a}$ & 0.46 & $53.72 \pm 6.79^{a}$ & $13.64 \pm 1.28$ \\
\hline$+\mathrm{NDF}+\mathrm{PPJ}$ & $1.99 \pm 0.11^{\mathrm{a}}$ & $13.79 \pm 1.65^{\mathrm{a}}$ & $1.18 \pm 0.09^{a}$ & $1.74 \pm 0.07^{\mathrm{ab}}$ & $6.51 \pm 0.13^{\mathrm{a}}$ & $7.71 \pm 0.16^{\mathrm{ab}}$ & 0.46 & $49.05 \pm 5.72^{a}$ & $13.30 \pm 2.27$ \\
\hline \multicolumn{10}{|l|}{ Tortilla } \\
\hline - NDF & $1.69 \pm 0.07$ & $2.87 \pm 0.37$ & $0.83 \pm 0.07$ & $3.81 \pm 0.65$ & $4.20 \pm 0.61$ & $7.74 \pm 1.21$ & 0.49 & $45.38 \pm 4.08$ & \\
\hline$+\mathrm{NDF}$ & $2.33 \pm 0.04^{c}$ & $16.67 \pm 1.62^{c}$ & $1.16 \pm 0.06^{c}$ & $3.27 \pm 0.36$ & $3.12 \pm 0.19$ & $12.17 \pm 1.27^{c}$ & $0.57^{c}$ & $35.68 \pm 3.76^{c}$ & $15.07 \pm 4.32$ \\
\hline
\end{tabular}

NDF = nopal dietary fiber; PPJ = prickly pear fruit jam; $(+)$ presence, $(-)$ absence; $Q E$, quercetin equivalents. ${ }^{*} \mathrm{~N} \times 6.25$. Data are the means \pm SD of three separate experiments. ${ }^{a}$ Bar significantly different $(p<0.05)$ from - NDF - PPJ. ${ }^{b} \mathrm{P}<0.05$ for bar + NDF + PPJ vs + NDF - PPJ. ${ }^{c} P<0.05$ tortilla + NDF vs - NDF. 
respectively), the ash content (1.16; 1.18 , respectively), but not the protein content (Table 1 ). No differences were observed in both fiber and ash content by adding PPJ to bars. On the other hand the addition of PPJ resulted in a dilution effect on protein content in both -NDF and +NDF bar formulations (Table 1). According to the FDA, both bars and tortillas can be declared as a high source of fiber because the contribution of these foods is at least $20 \%$ of the daily value per serving and is considered a good source of nutrients when the food intake ranged 10-19\%. An intake of 2,000 calories has been established as the reference for the energy demand per day while fiber content reference is $11.5 \mathrm{~g}$ of fiber per 1,000 calories [14]. Interestingly, the fiber in nopal is composed mainly by soluble fiber, resulting in a better water retention capacity in foods made with this component $[8,15]$.

The nopal contained in the formulations reduced the protein content in our products, which might be related with the increased water retention capacity by the fibers. It may also be due to a reduced amount of protein available since it has previously developed Maillard reactions [16] or complex with polysaccharides [17]. Futures studies must be conducted to support these assumptions.

The lipid content in bars was positively correlated with fat and vegetable oil in the formulation. The addition of NDF to the formulation of tortillas and bars resulted in a decrease in lipid content, which is associated with a dilution effect directly related to humidity content in the samples.

\section{Moisture content and water activity}

The addition of NDF in the formulation resulted in an increase in the moisture content of the bars $(6.78 \%)$, with higher content in those made with PPJ (7.71\%). The same effect was observed for tortilla, which showed an increase from $7.74 \%$ to $12.17 \%$. The -NDF bars did not show differences in humidity content (5.63\%) with the addition of PPJ (5.66\%). The water as a constituent of foods influences the stability, quality, physical properties and shelf life. The texture characteristics are closely related to moisture content, so this parameter directly contributes to the product quality and acceptance by consumers. High moisture content can cause plasticising or antiplasticising effects [18], and brittle materials with the consequent loss of crusty attribute [19].

The determination of water activity $\left(\mathrm{a}_{\mathrm{w}}\right)$ helps to predict the mechanical properties, stability and shelf life of food [19]. The addition of nopal to the bars produced no changes in $a_{w}(p<0.05)$ (Table 1$)$. Furthermore, the addition of NDF increased the $\mathrm{a}_{\mathrm{w}}$ of tortillas from 0.48 to 0.57 ; these values are below 0.7 , indicating a low risk of microbial growth; also chemical and enzyme reactivity diminishes, which would provide adequate life and preservation of the products during storage.

\section{Hardness and Color}

Hardness parameter did not show changes in -NDF bars $(63.21 \mathrm{~N})$ compared to those added with PPJ $(\mathrm{p}<0.05)$. Bars +NDF showed to be softer $(53.72 \mathrm{~N})$ than -NDF. Presence of PPJ did not modify bar hardness formulated with nopal (49.05 N, Table 1). The +NDF tortillas showed to be softer $(35.68 \mathrm{~N})$ than -NDF tortillas (45.38 $\mathrm{N})$. Texture generated as a result of the interaction between the components of the formulation is a relevant parameter which contributes to shelf life and acceptance of foods. In the bars, wheat protein provides viscous properties and act as a gelling and water retainer, influencing the texture through a gradual tightening [20]. Such effect could be associated with the water migration from carbohydrates (pectins, maltodextrins, starch and sugars) to proteins [20]. It is known that carbohydrates retain moisture, modifying texture and preventing loss of moisture as consequence. However these phenomena fail to prevent moisture transfer to and from the protein. The addition of soluble fiber, carbohydrates, with low digestibility or highly branched, in the formulation can increase the shelf life. Soluble fibers such as inulin and pectin, as well as maltodextrin are the most common agents used to increase the initial softness in bars after processing. The observed effects in this study could have implications in this field.

In thermal treated food, the color on the surface is an important feature for consumers, because it indicates the magnitude of heat treatment. In the case of -NDF bars the value of $\mathrm{L}$ * (lightness), which defines in a sample as black (0) or white (100) raging 58-63, having lower values in the $+\mathrm{NDF}$. The a value defines colors from red $(+)$ to green $(-)$, the -NDF bars showed values of $8-9$, changing to negative values $(-4$ to -3$)$ on + NDF bars, which indicates a change in color from red-orange to green. The $b *$ value, which defines colors from yellow $(+)$ to blue $(-)$, was determined within the range of 16-20 (data not shown).

In the +NDF tortillas we observed a decrease in $\mathrm{L}$ *, $a *$ and $b *$ values $(62.3,-7,22.48)$ compared to the NDF tortillas $(73.4,2.68,25.69)$, indicating darker tortillas with green color. The $\Delta \mathrm{E}^{*}$ value is an overall measure of the change in color that resulted in the different products formulation, comparing NDF and/or PPJ enhanced and control products (-NDF -PPJ). The limit value which defines the difference in color was established in 3.7 units, since this value has been recognized as the level to match the color in several studies [21]. Both, +NDF bars and +NDF tortillas showed difference $(\mathrm{p}<0.05)$ in overall color change $\left(\Delta \mathrm{E}^{*}\right)$ with values between 13 and 15 units, respectively (Table 1 ). Color change is a dynamic process in which color transition occurs during the baking procedure. Because the thermal processing was the same for all samples, this 
suggest that the color is influenced by the ingredients of the formulation, which has been reported for some cereals [22].

\section{Effect of intake on oxidative parameters}

To determine if the ingestion of the manufactured foods have a positive effect on the oxidative status, 28 healthy volunteers were subjected to a supplementation scheme. Anthropometric measurements of volunteers were: age (years) $=22 \pm 3.7$, stature $(\mathrm{cm})=177.4 \pm 5.7$ and 164.9 \pm 7.2 , body weight $(\mathrm{kg})=65.8 \pm 9.6$ and $56.9 \pm 6.4$, body mass index (BMI, $\left.\mathrm{kg} / \mathrm{m}^{2}\right)=21.7 \pm 2.5$ and $20.94 \pm$ 2.3 for men and women, respectively.

\section{Plasma antioxidant status}

The trolox-equivalent antioxidant capacity (TEAC) evaluated in plasma is usually considered to provide indications of the body's global antioxidant status. With respect to baseline, the supplementation over 21 days with nopalbased tortillas generated an increase $(\mathrm{p}<0.05)$ in plasma antioxidant capacity $(1.47 \mathrm{mmol} / \mathrm{L})$ of $10.53 \%$ (Figure 1 ). Statistically, the intake of tortilla caused a change in plasma TEAC, which is in agreement with previous reports [23], although some others have not found changes in plasma antioxidant activity after prolonged intake of foods with high content of phenolic compounds [24].

The total polyphenol concentrations in plasma after supplementation with + NDF tortilla showed a significant increase of $8.12 \%$ attaining levels of $7.67 \mathrm{mg} \mathrm{QE} / \mathrm{L}$ ( $\mathrm{p}<$ 0.05 ; Figure 1). This result agrees with previous reports [25]. No changes on TEAC and phenolic compounds content were detected after ingestion of $+\mathrm{NDF}+\mathrm{PPJ}$ bars. Similarly, no changes were detected on the levels of vitamin $A$ and $E$ after supplementation with +NDF tortillas or $+\mathrm{NDF}$ bars, which is consistent with previous reports [26]. Vitamin C levels in plasma showed an increase of $25 \%$ following the ingestion of +NDF tortillas $(77.91 \mathrm{mmol} / \mathrm{L})$ and +NDF bars $(78.13 \mathrm{mmol} / \mathrm{L})$ (Figure 1), which can be related to the absorption of this component supplied from the modified food or by a replacement effect of this vitamin by vitamin E, B or polyphenolic compounds [26].

\section{Oxidative stress biomarkers}

Lipid oxidation directed by free radicals is a fundamental feature of oxidant stress, therefore the quantification of the end products from lipid peroxidation like Propanedial (Malondialdehyde, MDA) level in plasma and erythrocytes is considered an excellent marker of oxidative status in vivo [27]. The plasma MDA concentration was significantly different $(\mathrm{p}<0.05)$ in respect to the baseline after supplementation with $+\mathrm{NDF}$ tortillas $(0.87$ $\mathrm{mol} / \mathrm{L})$ and $+\mathrm{NDF}+\mathrm{PPJ}$ bars $(0.96 \mathrm{~mol} / \mathrm{L})$, representing a decrease of $25 \%$ and $12 \%$, respectively (Figure 2). Low levels of MDA indicate that body lipids are preserved in larger proportion. It is feasible that antioxidant vitamins, along with various phytochemicals present in nopal (flavonols) and maize (hydroxycinnamic acids) contribute to maintain adequate oxidative status. This observation correlates with the levels of antioxidant vitamins and polyphenolic compounds (Figure 1), suggesting a strong contribution to the observed effect. The contribution of pigments and other phytochemicals with antioxidant activity in the prevention of oxidative damage in vivo should also be considered [28].

(2S)-2-amino-5-[[(2R)-1-(carboxymethylamino)-1-oxo3-sulfanylpropan-2-yl]amino]-5-oxopentano-ic acid (Glutathione) is the most potent cellular antioxidant. It is also a cofactor of the GSH-peroxidase family, which is related in the prevention of oxidation and cross-linking of proteins thiols. Therefore, the GSH:GSSG ratio is an important index of the body's oxidative status [29]. GSH levels were unchanged $(\mathrm{p}<0.05)$ after supplementation with either +NDF tortillas $(2.29 \mathrm{mmol} / \mathrm{L})$ or $+\mathrm{NDF}+\mathrm{PPJ}$ bars $(2.17 \mathrm{mmol} / \mathrm{L})$. Interestingly, the level of GSSG (0.17 $\mathrm{mmol} / \mathrm{L}$ ) showed a decrease of $19 \%$ from the baseline after the ingestion of +NDF tortillas, resulting in an increase of $23 \%$ of the GSH:GSSG ratio (Figure 2), reflecting an improved antioxidant status [13]. This result indicates that supplementation with tortilla reduces oxidative damage and increase the potential reduction of the cell.

Polyphenols have been considered as important contributors to the antioxidant activity of horticultural products [25]. Among polyphenols produced by nopal, 2-(3,4-Dihydroxyphenyl)-3,5,7-trihydroxy-4H-1-benzopyran-4-one dihydrate (quercetin) and its derivatives are relevant examples, as well as pigments like (2S)-4-[2-[(2S)-2-carboxy-6hydroxy-5-[(2S,3R,4S,5S,6R)-3,4,5-trihydroxy-6-(hydroxymethyl)oxan-2-yl] oxy-2,3-dihydroindol-1-yl] ethenyl]-2, 3 -dihydropyridine-2,6-dicarboxylic acid (betanin) and (2S)-1-[(2E)-2-[(2S)-2,6-dicarboxy-2,3-dihydro-1H-pyridin4ylidene]ethylidene] pyrrolidin-1-ium-2-carboxylate (indicaxanthin) due to its high antioxidant capacity. The scavenger and antioxidant activity of these compounds has been demonstrated in several chemical and biological systems $[11,30]$. These are absorbed from the nopal and prickly pear fruit, and are bioavailable in humans, reaching peak plasma concentrations of micromoles at three hours, suggesting that these phytochemicals have potential contribution to the protective effect. These results support the benefits of diets supplemented with nopal and prickly pear fruit as a via to reduce the risk of chronic degenerative diseases in which oxidative stress plays a pathogenic role.

\section{Healthy status indicators}

Glucose, cholesterol (total, HDL, LDL) and triglyceride levels are considered indicators of good health, therefore high levels of these are associated with an increased risk 

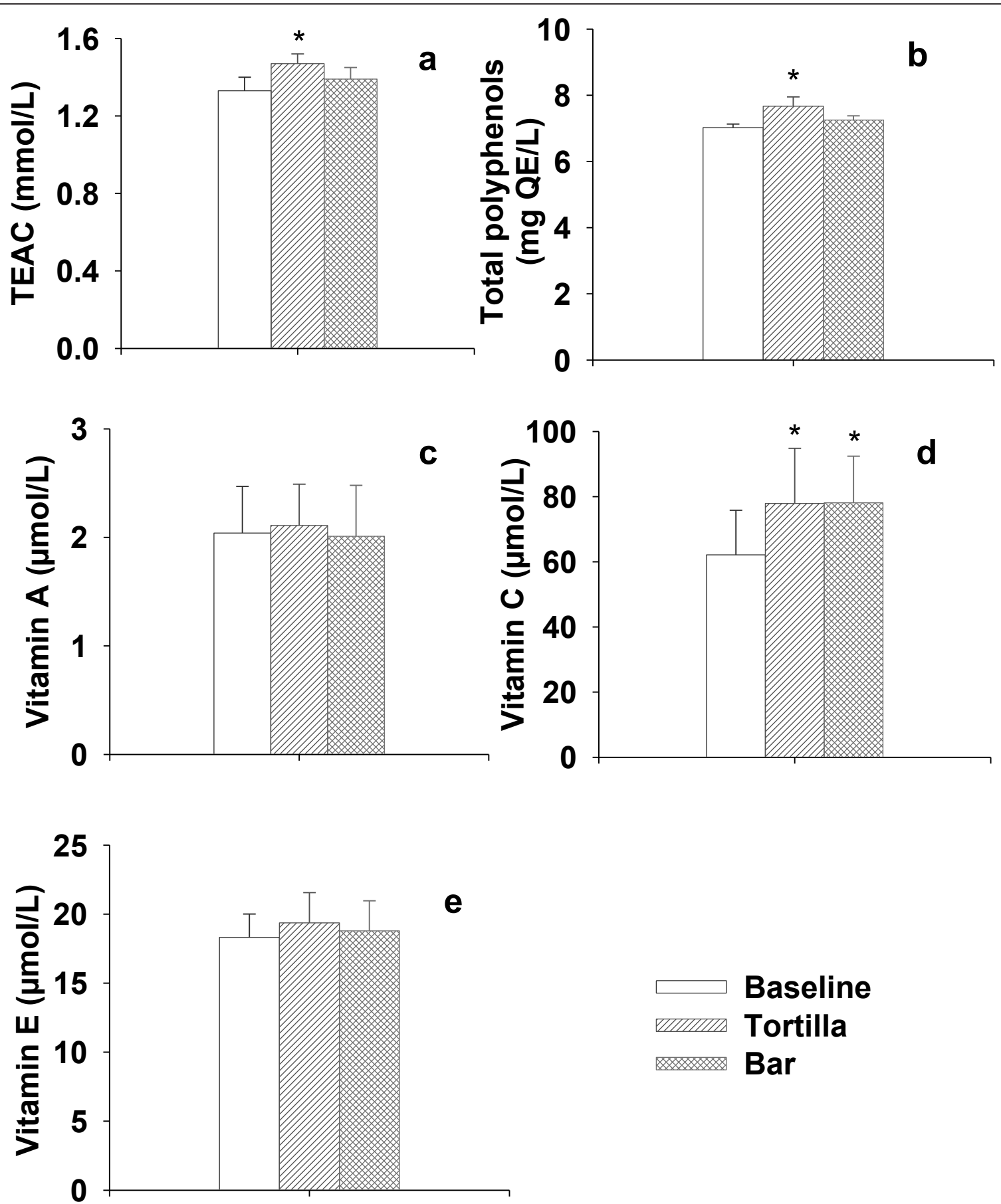

Figure 1 Plasma antioxidant status. a) Trolox equivalent antioxidant capacity (TEAC); b) Total polyphenols concentration; c) Vitamin A; d) Vitamin $C$ and e) Vitamin E levels in healthy volunteers.

of cardiovascular disease and chronic degenerative diseases. After supplementation with +NDF tortilla, glucose levels $(4.43 \mathrm{mmol} / \mathrm{L})$, total cholesterol $(4.27 \mathrm{mmol} / \mathrm{L})$, LDL $(1.96 \mathrm{mmol} / \mathrm{L})$ and triglycerides $(1.54 \mathrm{mmol} / \mathrm{L})$ showed significant changes ( $\mathrm{p}<0.05$ ), decreasing $17.52 \%$, $8.57 \%, 16.95 \%$ and $9.94 \%$, respectively (Figure 3 ). On the other hand, +NDF + PPJ bars only induced a significant decrease $(\mathrm{p}<0.05)$ in glucose $(469 \mathrm{mmol} / \mathrm{L})$ and LDL $(2.19 \mathrm{mmol} / \mathrm{L})$ levels of $12.66 \%$ and $7.20 \%$ respectively. These results indicate that $+\mathrm{NDF}$ tortillas have a higher functional effect compared with the +NDF bars. Several studies have identified components of dietary fiber 


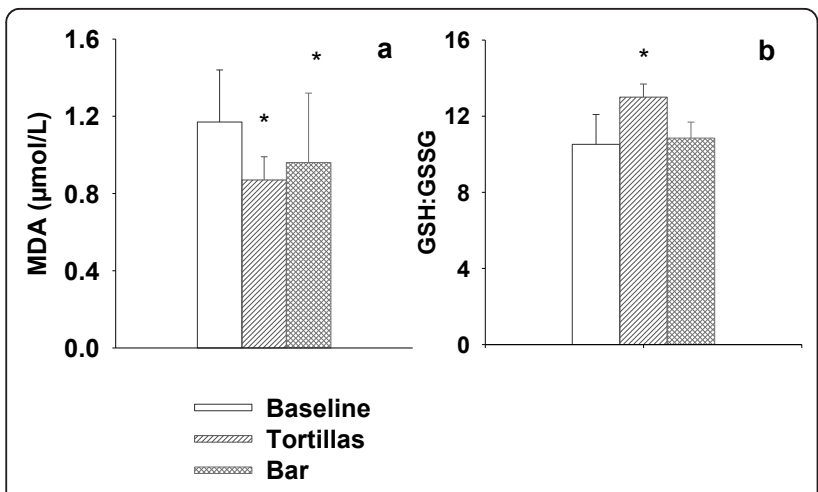

Figure 2 Oxidative stress biomarkers. a) Malondialdehyde levels (MDA); b) Ratio of reduced to oxidized glutathione (GSH:GSSG) in healthy volunteers.

(mucilage and pectin) as the main factor for these effects [31], although the action mechanism which generates an overall improvement in physical functioning is not yet clearly defined and therefore further studies should be conducted to provide a detailed explanation of this observed effect.

\section{Experimental}

Nopal and yellow prickly pear fruits from (Opuntia ficus-indica plants, cv. Milpa Alta) were obtained from commercial plantations in Milpa Alta, DF, Mexico. The prickly pear cactus stems (about 15-20 cm long; respiration rate of $11.2 \mu \mathrm{L} \mathrm{kg}^{-1} \mathrm{~s}^{-1}$ ) and fruits (about 140-190 g; respiration rate of $19.7 \mu \mathrm{L} \mathrm{kg}^{-1} \mathrm{~s}^{-1}$ ) were manually harvest (a day before being processed) by cutting the articulation with the 'mother cladode' during afternoon at end July, 2010. The cut zones were immersed in a solution of ascorbic acid (100 ppm) for $15 \mathrm{~min}$. Both stems and tunas were placed in a cover carton containers and transported to the laboratory by land. They were washed in a $\mathrm{NaOCl}$ solution $(200 \mathrm{ppm})$ at $4{ }^{\circ} \mathrm{C}$ for $15 \mathrm{~min}$ and dried very fast using a fan. Further they were selected and classified according to size, uniformity and freedom of defects. The respiration rate of the stems and fruits were determined using a closed system according to the methodology established by [32] and adapted to cladodes by [33]. Reagents 6-hydroxy-2,5,7,8tetrametilcromano-2-carboxylic acid (Trolox), 2,2'-azinobis (3-ethylbenzothiazoline-6-sulfunic acid) diammonium salt (ABTS), 1,4-bis(sulfanyl)butane-2,3-diol (dithiothreitol) and standards of (2R)-2-[(1S)-1,2-dihydroxyethyl]-4,5-dihydroxyfuran-3-one (ascorbic acid), (5R)-5-[(1S)-1,2-dihydroxyethyl] oxolane-2,3,4-trione (dehydroascorbic acid), (2E,4E,6E,8E)-3,7-dimethyl-9(2,6,6-trimethylcyclohexen-1-yl)nona-2,4,6,8-tetraen-1-ol (all-trans-retinol), 2,5,7,8-tetramethyl-2-(4,8,12-trimethyltridecyl)-3,4-dihydrochromen-6-ol ( $\alpha$-tocopherol) and 2-(3,4-dihydroxyphenyl)-3,5,7-trihydroxychromen-4- one (quercetin), were obtained from Sigma-Aldrich (St. Louis, MO). Methanol, propan-2-one (acetone), hexane and ethanol (HPLC grade) were purchased from JT Baker (Baker Mallinckrodt, Mexico).

\section{Nopal grounded}

Nopal previously blanched by immersion in water $\left(90^{\circ} \mathrm{C}\right.$, $15 \mathrm{~s})$ was immediately despinned using knives and grinded using a food processor (Osteriser ${ }^{\mathbb{B}}$ model 9110, Jarden Corporation, USA) at high speed for $45 \mathrm{~s}$ until a dispersion was obtained.

\section{Prickly pear fruit jam (PPJ)}

It consisted of a jam made with $62 \%$ prickly pear fruit pulp, $30 \%$ sucrose, $7 \%$ water, $0.05 \%$ pectin and $0.04 \%$ citric acid. The jam development process was carried out according to standard procedures reported previously [34].

\section{Bars}

Three type of bars were produced. Basic formulation included: $33 \%$ wheat flour (11\% of protein content, Molinos Mexico), $19.8 \%$ oat bran (Quaker), $0.3 \%$ sucrose (Danisco), $1.1 \%$ vegetable oil (Unilever), $0.3 \%$ salt (Sanudo), 0.1\% calcium carbonate (Calymar), 10.6\% liquid egg (Inova Alimentos), 1.9\% butter (Unilever), $0.1 \%$ pectin (Texture innovation company), $0.3 \%$ glucose syrup and $0.4 \%$ maltodextrins (Corn Products S.A de C. V.), all companies from Mexico. Nopal-based bars included in addition 32\% grounded nopal. The wet ingredients were mixed and then poured into pre-mixed dry ingredients. The resultant mixture was mixed thoroughly by hand, and thirty five grams were weighed out and pressed into rectangle-shaped casts $(10 \mathrm{~cm} \times 10 \mathrm{~cm} \times 2$ $\mathrm{cm}$ ) and rolled on a hollow cylinder, which was removed once bars were baked $\left(180^{\circ} \mathrm{C}, 20 \mathrm{~min}\right)$ using a TEDESCO oven (FTT 300, Coaxias do Sul/RS Brasil). A third type of bar was obtained by adding $15 \mathrm{~g}$ of PPJ inside the bars. The bars were packed at room temperature in polyethylene bags of high density and final weight was $40 \mathrm{~g}$. The elaboration process was repeated every seven days.

\section{Nopal-based tortillas}

Nopal based tortillas were made initially mixing 51.3\% corn flour nixtamalized (Maseca $\left.{ }^{\circledR}\right), 0.7 \%$ texturizer and softener (MEXELIN ${ }^{\circledR}$, Mexico) and $48 \%$ of ground nopal using a mixer (LENIN, Mexico) with a capacity of $50 \mathrm{~kg}$ for $10 \mathrm{~min}$. The resulting dough was allowed to steep for $5 \mathrm{~min}$ prior to processing it into tortilla disk and baked on a triple-pass, gas-fired baking oven (model MLR 30, LENIN, Mexico) at an average temperature of $280^{\circ} \mathrm{C}$ for $60 \mathrm{~s}$. The tortillas were vacuum-packed in Freshness Plus ${ }^{\mathrm{TM}}$ bags (Sealed Air, Duncan, SC, U.S.A.) containing $500 \mathrm{~g}$ of tortillas using a vacuum packaging 

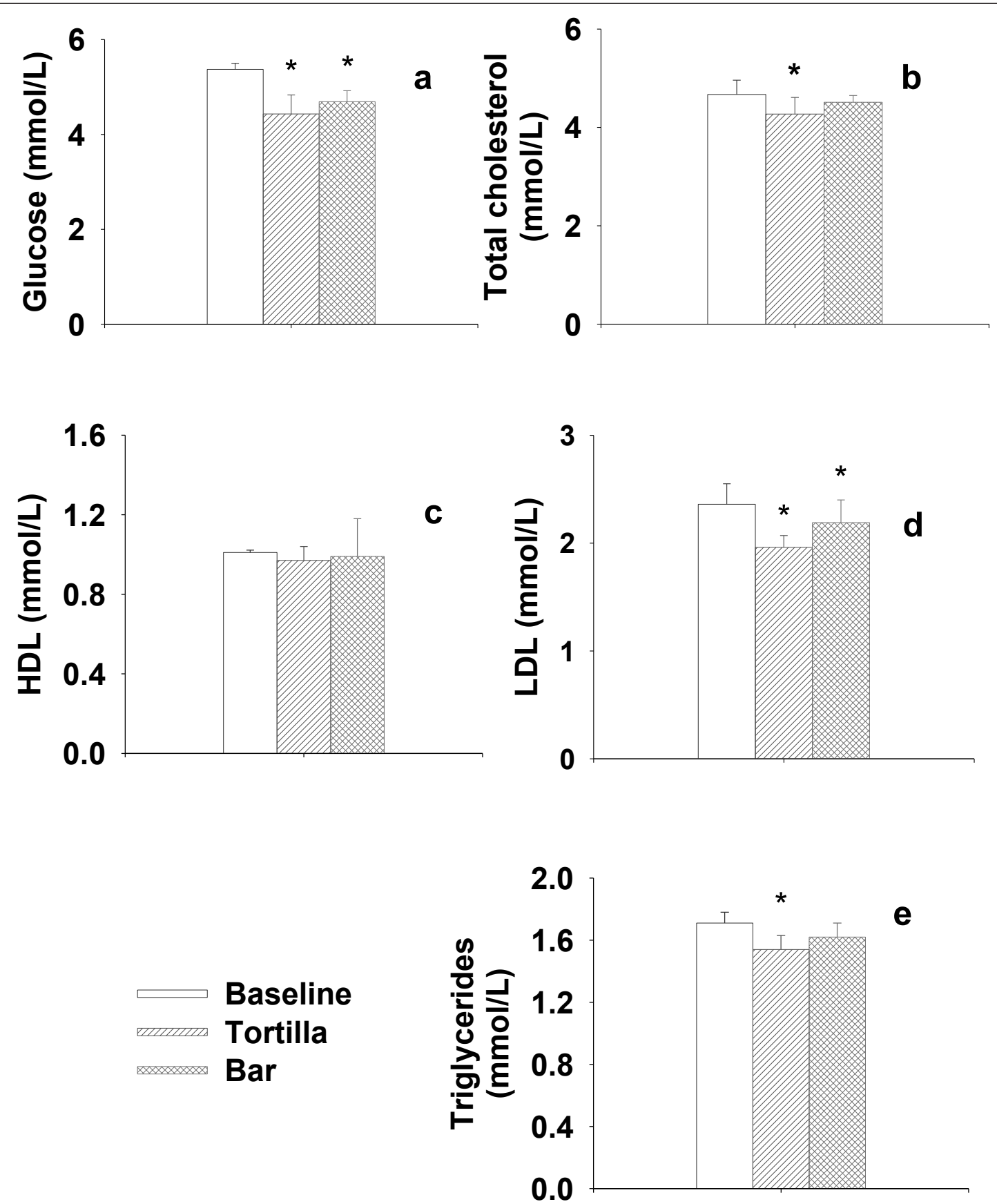

Figure 3 Healthy status indicators. Glucose (a), Total cholesterol (b), HDL (c), LDL (d) and Triglycerides (e) in healthy volunteers.

(EVD-4, TOREY, Mexico) at room temperature before being physicochemical and nutritionally evaluated. A batch of $40 \mathrm{~kg}$ of tortillas was made every week throughout intake period.

\section{Physicochemical analysis in bars and tortillas}

The content of total phenolic compounds (free and conjugated) expressed as mg quercetin equivalents (QE) was determined according to a previously described methodology [35]. The total dietary fiber (method 985.29) [36], ash (method 940.26) [36], protein (method 2001.1) [37], lipids (method 2003.05) [37], moisture (method 925.10) [37] and $a_{w}$ (method 978.18) [36] were also assessed.

\section{Color}

The color in the samples was determined using a Minolta colorimeter (CR-300, Konica Minolta Sensing Inc., 
Osaka Japan) and was expressed as the total color difference $\left(\Delta \mathrm{E}^{*}\right)$ according to the formula:

$$
\Delta E^{*}=\left[\left(L_{1}^{*}-L_{2}^{*}\right)^{2}+\left(a_{1}^{*}-a_{2}^{*}\right)^{2}+\left(b_{1}^{*}-b_{2}^{*}\right)^{2}\right]^{1 / 2}
$$

Where $L^{*}, a^{*}$ and $b *$ represent the parameters of luminosity, red-green and yellow-blue, respectively, between nopal enhanced and control products (without nopal).

\section{Hardness}

This parameter was determined as the maximum force (N) required to penetrate $5 \mathrm{~mm}$ into bars and tortillas (folded transversely into four parts), using a texture analyzer (Texture Technologies Corp, NY) with a circular probe of $14 \mathrm{~mm}$ diameter at a speed of $1 \mathrm{~mm} / \mathrm{s}$ [38].

\section{Subjects and study design}

Twenty-eight volunteers (16 women and 12 men) were recruited with prior consent. The health of the participants was determined by anthropometric measures and a questionnaire under the following criteria: 1) no history of gastrointestinal, kidney, liver, or cardiovascular disease, 2) not using antibiotics or vitamin or mineral supplements six weeks before the start of the study and 3) no smoking. The protocol was approved by the Ethics Committee for Human Studies of the San Luis Potosí Autonomous University (UASLP).

By a double treatment, and completely random crosslinked, 28 healthy volunteers supplemented their diet with $100 \mathrm{~g}$ of nopal-based tortilla (5 pieces) or $40 \mathrm{~g}$ of nopal-based bar (1 piece) filled with prickly pear fruit jam (PPJ), twice daily for three weeks with no supplementation period of six weeks between each treatment. Subjects were allowed to continue their usual eating habits, with the restriction of omitting any horticultural products in their diet.

Blood samples from the volunteers were collected after an overnight fast $\geq 8 \mathrm{~h}$ by venipuncture in tubes containing EDTA (1 mg/mL) before (baseline) and at the end of each supplementation period. The samples were stored at $4^{\circ} \mathrm{C}$ and subjected within the next $2 \mathrm{~h}$ to centrifugation at $3000 \times g$ for $10 \mathrm{~min}$ to separate the plasma from erythrocytes. Samples were stored at $-40^{\circ} \mathrm{C}$ for subsequent biochemical analysis (TEAC, total polyphenols, vitamins, malondialdehyde, glucose, cholesterol, HDL, LDL, triglycerides). The red blood cells were washed with phosphate buffered saline $(5 \mathrm{mmol} / \mathrm{L}, \mathrm{pH}$ 7.4) and were analyzed immediately.

\section{HPLC Procedures}

A HPLC system (Varian Inc., Walnut Creek, CA) composed by a ternary pump (Solvent Delivery System
Model 9012), UV/Vis detector (Model 9050), Refractive Index detector (Model Star 9040) and a Fluorometric detector (Model 1200) was used.

\section{Oxidative status indicators TEAC}

The trolox-equivalent antioxidant capacity (TEAC) was determined according to a previously reported method [39].

\section{Total polyphenols in plasma}

Total polyphenols were measured using the FolinCiocalteau method [40]. The absorption at $376 \mathrm{~nm}$ was measured spectrophotometrically. The total polyphenol content was expressed as quercetin equivalent per liter.

\section{Vitamins}

The (2E,4E,6E,8E)-3,7-dimethyl-9-(2,6,6-trimethylcyclohexen-1-yl)nona-2,4,6,8-tetraen-1-ol (all-trans-retinol) and 2,5,7,8-tetramethyl-2-(4,8,12-trimethyltridecyl)-3,4dihydrochromen-6-ol ( $\alpha$-tocopherol) were determined using HPLC as reported before [23]. (2R)-2-[(1S)-1,2dihydroxyethyl]-4,5-dihydroxyfuran-3-one (ascorbic acid) was determined in $500 \mu \mathrm{L}$ of plasma using $1.0 \mathrm{mM}$ of 1,4-bis(sulfanyl)butane-2,3-diol (dithiothreitol) as reducing agent. The extraction, HPLC separation and spectrophotometric detection at $266 \mathrm{~nm}$ were carried out as previously reported [41].

\section{Propanedial (Malondialdehyde, MDA)}

It was evaluated in plasma by colorimetric reaction with 2-sulfanylidene-1,3-diazinane-4,6-dione (thiobarbituric acid) as previously reported [39].

(2S)-2-amino-5-[[(2R)-1-(carboxymethylamino)-1-oxo-

3-sulfanylpropan-2-yl]amino]-5-oxopenta-noic acid

\section{(Glutathione)}

GSH and GSSG in red blood cells were assessed by HPLC ion exchange reverse phase using an aminopropyl silica column $(250 \times 30 \mathrm{~mm}$ inside diameter, Supelco $)$ according to the method described before [42].

\section{Glucose, cholesterol and triglycerides}

Glucose levels were determined in serum using the GAGO20 kit (Sigma Aldrich), while triglycerides levels, total cholesterol and HDL and LDL fractions were determined using the kits ETGA-200, E2CH-100 and E2HL100 (Bioassays Systems, California, USA), respectively. In all cases procedures specified by the supplier were followed.

\section{Statistical analysis}

The experiments were carried out using a completely randomized design. Values are expressed as mean \pm SD of three physicochemical analyses and twenty-eight independent analysis of biofunctional activity. Significant difference $\mathrm{p}<0.05$ was determined using paired $\mathrm{t}$ test. 


\section{Conclusions}

In this study nopal supplemented products, tortillas and bars, were produced having suitable physicochemical characteristics to be marketed. Interestingly a high content of bioactive components (i.e., dietary fiber and polyphenols) were achieved in the products.

Daily supplementation with nopal-based tortilla over 21 days, improved the oxidative status of healthy humans. Experimental evidence includes the increased in redox state (TEAC) and the decreased oxidative status on plasma lipids (MDA levels), as well as lower concentrations of the main antioxidant agent in the oxidized form in erythrocytes (GSSG). In addition, a diminution of glucose, cholesterol (total, LDL) and triglycerides levels were detected, which together reduce the risk of various chronic diseases. The relative low levels of antioxidant vitamins provided by the nopalbased products cannot generate the observed effects by themselves. Therefore, other compounds with antioxidant activity present in nopal, prickly pear fruit and compounds of the formulation should be involved in the observed findings.

\section{Acknowledgements \\ The authors are grateful to Dr. Luis Cedeño from UNAM Catalysis Unit for useful discussion and Mr. David Nava Carus from HH San Luis Potosi for reading and to correct the paper.}

\section{Author details}

${ }^{1}$ Centro de Investigación y Estudios de Posgrado (CIEP), Universidad Autónoma de San Luis Potosí, SLP,78290, México C.P. ${ }^{2}$ Centro de Investigación en Alimentos y Desarrollo (CIAD), Cd. Cuauhtémoc, Chihuahua, 31570, México. C.P. ${ }^{3}$ Centro de Investigación en Ciencia y Tecnología de Alimentos (CICyTA), Tulancingo de Bravo, Hidalgo, 43600, México. C.P.

\section{Authors' contributions}

JCG conceived of the study, participated in its design and coordination, performed data analysis and contributed to the drafting of the manuscript. JJO was involved in the products physicochemical assessment, the chromatographic determinations and drafting of the manuscript. SRM was the subject's coordinator who conducted volunteer interviews, set up database used to collect and organize data and drafting of the manuscript. RES was involved in analytical method development and data collection. LMP conducted statistical analysis and drafting of the manuscript. DJP was in charge of some plasma antioxidant status determinations. All authors have read and approved the final manuscript.

\section{Competing interests}

The authors declare that they have no competing interests.

Received: 5 November 2010 Accepted: 3 March 2011

Published: 3 March 2011

\section{References}

1. Jew S, AbuMweis SS, Jones PJ: Evolution of the human diet: linking our ancestral diet to modern functional foods as means of chronic disease prevention. J Med Food 2009, 12:925-934.

2. Sun-Waterhouse D, Melton LD, O'Connor CJ, Kilmartin PA, Smith GB: Effect of Apple Cell Walls and Their Extracts on the Activity of Dietary Antioxidants. J Agric Food Chem 2008, 56:289-295.

3. ALINORM 09/32/26: Report of the 30th session of the Codex committee on nutrition and foods for special dietary uses 3-7 November 2008.
2009, 46[http://www.codexalimentarius.net/download/report/710/al32_26e. pdf], Appendix II.

4. Sánchez-Alonso I, Borderias AJ: Technological effect of red grape antioxidant dietary fibre added to minced fish muscle. Int J Food Tech 2008, 43:1009-1018.

5. Rodríguez R, Jiménez A, Fernández-Bolaños J, Guillén R, Heredia A: Dietary fiber from vegetable products as source of functional ingredients. Trends Food Sci Tech 2006, 17:3-15.

6. Sáyago-Ayerdi SG, Arranz S, Serrano J, Goñi I: Dietary fiber content and associated antioxidant compounds in Roselle flower (Hibiscus sabdariffa L.) Beverage. J Agric Food Chem 2007, 55:7886-7890.

7. Stintzing FC, Carle R: Cactus stems (Opuntia spp.): A review on their chemistry, technology and uses. Mol Nutr Food Res 2005, 49:175-194.

8. Saenz C: Processing technologies: an alternative for cactus pear (Opuntiaspp.) fruits and cladodes. J Arid Environ 2000, 46:209-225.

9. Guevara-Arauza JC: Efectos Biofuncionales del Nopal y la Tuna. Horticultura Internacional 2009, 71:18-24.

10. Wolf KL, Liu RH: Cellular antioxidant activity (CAA) assay for assessing antioxidants, foods, and dietary supplements. J Agric Food Chem 2007 55:8896-907.

11. Butera D, Tesoriere L, Di Gaudio F, Bongiorno A, Allegra M, Pintaudi AM, Kohen R, Livrea MA: Antioxidant activities of Sicilian prickly pear (Opuntia ficus-indica) fruit extracts and reducing properties of its betalains: betanin and indicaxanthin. J Agric Food Chem 2002, 50:6895-6901.

12. Wang $R$, Zhou W: Stability of tea catechins in the bread making process. J Agric Food Chem 2004, 52:8224-8229.

13. Rohn S, Rawel H, Kroll J: Antioxidant activity of protein-bound quercetin. J Agric Food Chem 2004, 52:4725-4729.

14. Appendix B: Additional Requirements for Nutrient Content Claims, Guidance for Industry A food Labeling Guide, FDA U.S. Food and Drug Administration: U.S. Department of Health and Human Service, Center for Food Safety and Applied Nutrition and Drug Administration. Georgia, United States; 2009 [http://www.fda.gov/Food/ GuidanceComplianceRegulatory/nformation/GuidanceDocuments/ FoodLabelingNutrition/FoodLabelingGuide/ucm064916.htm].

15. Medina-Torres L, Brito de la Fuente E, Torrestiana-Sanchez B, Alonso S: Mechanical properties of gels formed by mixtures of mucilage gum (Opuntia ficus indica) and carrageenans. Carbohyd Polym 2003, 52:143-150.

16. Damoradan S: Amino acids, peptides and proteins. In Food Chemistry. Edited by: Damoradan S, Parkin KL, Fennema OR. Marcel Dekker Inc; 2007:322-429.

17. Chao YC, Chiang BH: Cream formation in a semifermented tea. J Sci Food Agr 1999, 79:1767-1774.

18. Gates FK, Dobraszczyk BJ, Stoddard FL, Sontag-Strohm T, Salovaara H: Interaction of heat-moisture conditions and physical properties in oat processing. 1. Mechanical properties of steamed oat groats. J Cereal Sci 2008, 47:239-244.

19. Lewicki PP: Water as determinant of food engineering properties. A review. J Food Eng 2004, 61:483-495.

20. Shaun PA: Mechanisms of nutrition bar hardening: Effect of hydrolyzed whey protein and carbohydrate source. PhD thesis and dissertations Utah State University; 2008.

21. Seghi RR, Hewlett ER, Kim J: Visual and instrumental colorimetric assessments of small colour differences on translucent dental porcelain. J Dent Res 1989, 68:1760-1764.

22. Poinot P, Arvisenet G, Grua-Priol J, Colas D, Fillonneau C, Le Bail A, Prost C: Influence of formulation and process on the aromatic profile and physical characteristics of bread. J Cereal Sci 2008, 48:686-697.

23. Tesoriere L, Butera D, Pintaudi AM, Allegra M, Livrea MA: Supplementation with cactus pear (Opuntia ficus-indica) fruit decreases oxidative stress in healthy humans: a comparative study with vitamin C. Am J Clin Nutr 2004, 80:391-395.

24. McKay D, Chen O, Yeum KJ, Matthan NR, Lichtenstein AH, Blumberg JB: Chronic and acute effects of walnuts on antioxidant capacity and nutritional status in humans: a randomized, cross-over pilot study. Nutr J 2010, 9:21.

25. Manach C, Scalbert A, Morand C, Rémésy C, Jiménez L: Polyphenols: food sources and bioavailability. Am J Clin Nutr 2004, 79:727-747.

26. Gey KF: Vitamins E plus $E$ and interacting conutrients required for optimal health. A critical and constructive review of epidemiology and 
supplementation data regarding cardiovascular diseases and cancer. Biofactors 1998, 7:113-174.

27. Janero DR: Malondialdehyde and thiobarbituric acid as diagnostic indices of lipid peroxidation and peroxidative tissue injury. Free Radic Biol Med 1990, 9:515-540.

28. Tesoriere L, Butera D, D'Arpa D, di Gaudio F, Allegra M, Gentile C: Increased resistance to oxidation of betalain-enriched human low density lipoproteins. Free Radic Res 2003, 37:689-696.

29. Stocker R, Frei B: Endogenous antioxidant defenses in human blood plasma.Edited by: Sies H. Oxidative stress: oxidants and antioxidants. London: Academic Press; 1991:213-243.

30. Kanner J, Harel S, Granit R: Betalains-a new c1ass of dietary cationized antioxidants. J Agric Food Chem 2001, 49:5178-5185.

31. Costacou T, Mayer-Davis EJ: Nutrition and prevention of type 2 diabetes. Ann Rev Nutr 2003, 23:147-170.

32. Haggar PE, Lee DS, Yam KL: Application of an enzyme kinetics based respiration model to closed system experiments for fresh produce. $J$ Food Proc Eng 1992, 15:143-157.

33. Guevara JC, Yahia EM, Beaudry RM, Cedeño L: Modeling the influence of temperature and relative humidity on respiration rte of prickly pear cactus cladodes. Posth Biol Tech 2006, 41:260-265.

34. Santanu B, Shivhare US: Rheological, textural, micro-structural and sensory properties of mango jam. J Food Eng 2010, 100:357-365.

35. De la Parra C, Serna-Saldiva SO, Liu RH: Effect of processing on the phytochemical profiles and antioxidant activity of corn for production of masa, tortillas, and tortilla chips. J Agric Food Chem 2007, 55:4177-4183.

36. Horwitz W, Latimer G: Official Methods of Analysis of AOAC International, Gaithersburg MA, USA Association of Official Analytical chemist; 2000.

37. Horwitz W, Latimer G: Official Methods of Analysis of AOAC International, Gaithersburg MA, USA Association of Official Analytical chemist; 2005.

38. Guevara JC, Yahia E, Brito de la Fuente E, Biserka SP: Effects of elevated concentrations of $\mathrm{CO}_{2}$ in modified atmosphere packaging on the quality of prickly pear cactus stems (Opuntia spp). Postharvest Biol Tec 2003, 29:167-176.

39. Rice-Evans C, Miller NJ: Total antioxidant status in plasma and body fluids. Methods Enzymol 1994, 234:279-293.

40. Swain T, Hillis E: The pehenolic constituents of Prunus domestica. The quantitative analysis of phenolic constituents. J Sci Food Agric 1959, 10:63-68.

41. Lazzarino G, Di Pierro D, Gavazzi B, Cerroni L, Giardina B: Simultaneous separation of malondialdehyde, ascorbic acid and adenine nucleotide derivatives from biological sample by ion-paring high performance chromatrography. Anal Biochem 1991, 197:191-196.

42. Martin J, White NH: Fluorimetric determination of oxidized and reduced GSH in cells and tissues by high-performance liquid chromatography following derivatization with dansyl chloride. J Chromatogr 1991, 568:219-225

doi:10.1186/1752-153X-5-10

Cite this article as: Guevara-Arauza et al: Biofunctional activity of tortillas and bars enhanced with nopal. Preliminary assessment of functional effect after intake on the oxidative status in healthy volunteers. Chemistry Central Journal 2011 5:10.

Publish with ChemistryCentral and every
scientist can read your work free of charge
"Open access provides opportunities to our
colleagues in other parts of the globe, by allowing
anyone to view the content free of charge."
W. Jeffery Hurst, The Hershey Company.
- available free of charge to the entire scientific community
- peer reviewed and published immediately upon acceptance
- cited in PubMed and archived on PubMed Central
- yours - you keep the copyright
Submit your manuscript here:
http://www.chemistrycentral.com/manuscript/

